\title{
IMPLEMENTASI KECERDASAN INTRAPERSONAL MELATIH KEPEMIMPINAN ANAK
}

\author{
Eksil Sabe \\ Sekolah Tinggi Agama Kristen Terpadu Pesat Salatiga \\ Eksilsabe@gmail.com
}

\begin{abstract}
The purpose of this study is to provide understanding for children so that they are able to implement intrapersonal intelligence in their lives and to train the leadership that is within them. Children are able to understand the people around them, namely by understanding their emotions, behavior, moods, and they are even able to build good relationships with many people. Thus children are able to implement the intrapersonal intelligence that is within them to train their leadership. In this study, the authors also used the library research method where the data sources were taken from the library without conducting field research. After the research was carried out, the results of the study were when children were able to implement intrapersonal intelligence, the children would more easily understand other people and not become anti-social children. There is also a need for support from parents and also cooperation from teachers so that children are able to improve leadership in themselves through the application of intraopersonal intelligence.
\end{abstract}

Keywords: Intrapersonal Intelligence, Leadership, Children

\section{Abstraksi}

Tujuan dari penelitian ini adalah untuk memberikan pemahaman bagi anak sehingga mereka mampu mengimplementasikan kecerdasan intrapersonal dalam kehidupan mereka dan untuk melatih kepemimpinan yang ada dalam diri mereka. Anak mampu memahami orang-orang yang ada disekitar mereka yaitu dengan cara memahami emosi, perilaku, suasana hati, bahkan mereka mampu untuk menjalin relasi yang baik dengan banyak orang. Dengan demikian anak mampu mengimplementasikan kecerdasan intrapersonal yang ada dalam diri mereka untuk melatih kepemimpinannya. Dalam penelitian ini juga penulis menggunakan metode penelitian kepustakaan dimana sumber data yang di ambil dari perpustakaan tanpa adanya melakukan riset lapangan. Setelah penelitian dilakukan maka hasil dari penelitian yaitu ketika anak mampu mengimplemantasikan kecerdasan intrapersonal maka anak akan lebih mudah memahami orang lain dan tidak menjadi anak yang anti sosial. Perlunya juga dukungan dari orangtua dan juga kerja sama dari guru sehingga anak mampu meningkatkan kepemimpinan dalam dirinya lewat penerapan kecerdasan intraopersonal.

Kata Kunci : Kecerdasan Intrapersonal, Kepemimpinan, Anak 


\section{PENDAHULUAN}

Kecerdasan intrapersonal sangat berhubungan untuk memahami orang lain. Kecerdasan intrapersonal mendorong keberhasilan seseorang dalam mengatur hubungan antar individu dua keterampilan itu merupakan kemampuan untuk mengenali dan menerima perbedaan perbedaan antar individu dan kemampuan untuk mengenali emosi, suasana hati, perspektif, dan motifasi orang. ${ }^{1}$ Dalam hal ini banyak hal yang dapat diperlajari anak dalam hal memahami dan melihat perbedaan yang ada disekitar mereka.

Penulis mengangkat judul ini agar anak mampu memahami dan mengimplementasikan kecerdasan intrapersonal di lingkungan mereka masing-masing. Seorang anak bisa dilihat apakah memiliki kecerdasan intrapersonal dalam dirinya atau tidak, dengan kita melihat cara anak menjalin relasi dengan orang-orang yang ada di sekitar mereka.

Anak yang tidak memiliki kecerdasan intrapersonal dalamm dirinya mengalami anti sosial. Contohnya, kurang peduli dengan orang lain, sulit memahami orang lain, dan suka mementingkan diri sendiri. Oleh sebab itu, penulis meneliti hal ini agar anak-anak bisa membuka pikiran, dan

\footnotetext{
${ }^{1}$ Ana Fitrotun Nisa, "Implementasi Multiple Intelligences Dalam Pendidikan Dasar," Jurnal pendidikan dasar islam 7, no. 2 (n.d.),

https://www.neliti.com/id/publications/284542/imp lementasi-multiple-intelligences-dalampendidikan-dasar.
}

mendapat wawasan baru mengenal cara mengimplementasikan kecerdasan intrapersonal dalam kehidupan mereka setiap hari. Melalui penelitian ini juga, harapan penulis agar anak-anak mampu menciptakan relasi yang baik dengan banyak orang dan harapan penulis anakanak tidak memiliki sikap antisosial dengan orang-orang yang ada disekitar mereka dan anak-anak tidak tumbuh menjadi anak yang suka mementingkan dirinya sendiri. Oleh sebab itu, pentingnya kecerdasan intrapersonal di terapkan agar untuk meningkatkan kepemimpinan dalam diri anak juga.

Penerapan kecerdasan intrapersonal mengapa mampu meningkatkan kepemimpinan, karena dalam hal ini anak bisa belajar banyak dari orang lain. Anak juga bisa lebih memahami banyak tentang sikap dan karakter orang lain. Oleh karena itu, manfaatnya anak bisa berbaur dengan banyak orang dan orang lain bisa di untungkan lewat apa yang anak lakukan.

Dalam hal ini ada 9 kecerdasan yang dimiliki oleh setiap orang, namun penulis hanya mengambil satu dari sembilan kecerdasan tersebut yaitu kecerdasan intrapersonal. 


\section{METODE PENELITIAN}

Penelitian yang digunakan adalah penelitian kepustakaan atau literatur. Riset pustaka memanfaatkan sumber perpustakaan untuk memperoleh data penelitian. Tegasnya riset pustaka membatasi kegiatannya hanya pada bahanbahan koleksi perpustakaan saja tanpa melakukan riset lapangan. Riset kepustakaan atau sering juga disebut study pustaka ialah serangkain kegiatan yang berkenaan dengan metode pengumpulan data pustaka, membaca dan mencatat serta mengolah bahan penelitian. ${ }^{2}$

Tujuan penelitian yaitu membuka pola pikir anak sehingga anak mampu mengimplementasikan kecerdasan intrapersonal dalam kehidupan mereka dan anak tidak memiliki rasa antisosial lingkungan. Harapan penulis juga anak bisa meningkatkan kepemimpinan yang ada dalam dirinya.

Oleh karena itu, penulis melakukan penelitian ini, sehingga anakanak yang memiliki kecerdasan intrapersonal dalam dirinya bisa lebih memahami dan anak mampu menerapkannya dalam kehidupan mereka

\footnotetext{
${ }^{2}$ Mestika Zed, Metode Penelitian Kepustkaan (Jakarta, 2008),

https://books.google.co.id/books?id=iIV8zwHnGo $0 \mathrm{C} \&$ printsec $=$ frontcover $\& \mathrm{dq}=$ penelitian + kepustak aan+adalah \&hl=id\&sa=X\&ved=2ahUKEwif_Zvu1 p3vAhWH7nMBHdXzAakQ6AEwAHoECAEQA $\mathrm{g} \# \mathrm{v}=$ onepage $\& \mathrm{q}=$ penelitian kepustakaan adalah $\& \mathrm{f}=$ false.
}

sehari-hari untuk meningkatkan jiwa kepemimpinan anak.

\section{PEMBAHASAN}

\section{Definisi kecerdasan Intrapersonal}

Berdasarkan beberapa sumber yang ada penulis akan menuangkan hasil dari penulisan ini yaitu tentang bagaimana anak dapat mengimplementasikan kecerdasan intarpersonal yang ada dalam dirinya untuk melatih kepemimpinan anak itu sendiri.

Kecerdasan interpersonal adalah kemampuan untuk berhubungan dengan orang-orang di sekitar kita. Kecerdasan ini adalah kemampuan untuk memahami dan memperkirakan perasaan, tempramen, suasana hati, maksud dan keinginan orang lain dan menanggapinya secara positif. ${ }^{3}$ Dalam hal ini kecerdasan intrapersonal dapat membangun kedekatan, pengaruh, serta membangun relasi dengan orang lain.

Mork mengemukkan Bahwa kecerdasan interpersonal adalah kemampuan untuk membaca tanda dan isyarat sosial, komunikasi verbal dan nonverbal dan mampu menyesuaikan gaya komunikasi dengan cepat. Gardner juga menyatakan bahwa kecerdasan interpersonal adalah kemampuan memahami, pikiran, sikap, dan perilaku

\footnotetext{
${ }^{3}$ May Lwin et al., Cara Mengembangkan Berbagai Komponen Kecerdasan (Yogyakarta: Prentice-Hall Inc, 2005).
} 
orang lain. Selanjutnya, Insenberg dan Jolongo mengutarakan bahwa kecerdasan interpersonal dapat distimulasi dan dikembangkan melalui kegitan bermain. ${ }^{4}$ Oleh sebab itu kecerdasan intrapersonal ini, lebih bertujuan agar anak mampu memahami orang-orang yang ada di sekitar mereka yaitu dengan melihat suasana hati, perasaan orang lain dan juga tempramen mereka. Dengan demikian anak lebih mudah menjalin relasi dengan orang lain dan lebih memahami orangorang yang ada di sekitar mereka.

Kecerdasan interpersonal juga didefinisikan adalah kemampuan berpikir lewat berkomunikasi dengan orang lain. Ini mengacu pada keterampilan manusia, dapat dengan mudah membaca, berkomunikasi, dan berinteraksi dengan orang lain. ${ }^{5}$ Artinya dalam hal ini dalam mengimplementasikan kecerdasan intrapersonal dalam diri anak maka anak bisa lebih banyak melakukan komunikasi dengan banyak orang sehingga anak lebih mudah memiliki banyak keterampilan yang kreatif dalam diri anak untuk berinteraksi atau berkomunikasi dengan banyak orang. Sehingga hal ini juga bisa melatih kepemimpinan yang ada dalam diri mereka. Dalam jurnal juga ada

\footnotetext{
${ }^{4}$ Aroffa Acesta, Kecerdasan Kinestetik Dan Interpersonal Serta Pengembangannya (Surabaya, 2019).

5 Yuliani Nurani Sujiono, Metode Pengembangan Kognitif (Jakarta, 2009).
}

beberapa definisi kecerdasan intrapersonal.

Kecerdasan intrapersonal adalah kemampuan untuk mengenali diri sendiri dengan memiliki konsep diri yang jelas serta citra diri yang positif. Artinya seorang anak jika memiliki kecerdasan intrapersonal dan dapat menerapkannya maka, anak dapat mengenali dirinya dengan postif.

Kecerdasan intrapersonal juga adalah adalah salah satu dari delapan kecerdasan ganda yang dikemukakan oleh Gardner dalam bukunya "Frames of Mind: The Theory of Multiple intelligences". Kecerdasan interpersonal adalah kemampuan untuk mengamati dan mengerti maksud, motivasi dan perasaan orang lain. Seorang dapat melatih kepemimpinan mereka dengan mengamati dan mengerti maksud, motifasi dan perasaan orang lain, oleh karena itu, anak dapat memimpin orang lain dan juga dapat memimpin dirinya sendiri lewat hal ini.

Kecerdasan intrapersonal juga memiliki tiga dimensi yaitu Social sensitivity (sensitivitas sosial), kemampuan untuk merasakan dan mengamati reaksireaksi atau perubahan orang lain yang ditunjukkannya baik secara verbal maupun non verbal. anak yang memiliki sensitivitas yang tinggi akan mudah memahami dan menyadari adanya reaksireaksi tertentu dari orang lain, entah 
reaksi tersebut positif ataupun negatif. Social insight, kemampuan seseorang untuk memahami dan mencari pemecahan masalah yang efektif dalam satu interaksi sosial, sehingga masalah-masalah tersebut tidak menghambat apalagi menghancurkan relasi sosial yang telah di bangun. Juga terdapat kemampuan dalam memahami situasi sosial dan etika sosial sehingga anak mampu menyesuaikan dirinya dengan situasi tersebut. Pondasi dasar dari social insight ini adalah berkembangnya kesadaran diri anak secara baik, kesadaran diri yang berkembang akan membuat anak mampu memahami keadaan dirinya baik keadaan internal maupun eksternal.Social communication, penguasaan keterampilan komunikasi sosial merupakan kemampuan individu untuk menggunakan proses komunikasi dalam menjalin dan membangun hubungan interpersonal yang sehat. Dalam proses menciptakan, membangun dan mempertahankan relasi sosial, maka seseorang membutuhkan sarananya, tentu saja sarana yang digunakan adalah melalui proses komunikasi, yang mencakup baik komunikasi verbal, non verbal maupun komunikasi melalui penampilan fisik. Keterampilan komunikasi yang harus dikuasai adalah keterampilan mendengarkan afektif, berbicara afektif, keterampilan publik speaking dan keterampilan menulis secara efektif. Nah, dalam 3 dimensi ini juga anak dapat mengembangakan penerapan impelemnatasi kecerdasan intrapersonalnya dan juga anak dapat melatih kepemimpinan yang ada dalam dirinya.

\section{Pentingnya Kecerdasan Intrapersonal}

Ada beberapa alasan penting mengapa memiliki kecerdasan intrapersonal tingkat tinggi bukan hanya penting tetapi juga merupakan dasar bagi kesejahteraan anak, khususnya ketika anak menjadi orang dewasa. Berikut alasannya : Pertama, ntuk menjadi orang dewasa yang sadar secara sosial dan mudah menyesuaikan diri. Artinya jika hal ini sudah di tanamkan dalam diri anak makan ketika anak dewasa nanti mereka tidak menyusahkan diri sendiri dan juga orang lain. Kedua, menjadi berhasil dalam pekerjaan. Jika anak memiliki kecerdasan intrapersonal dalam dirinya, maka anak mampu berpikir kreatif tentang apa yang membuat hidupnya berhasil.

Ketiga, demi kesejahteraan emosional dan fisik. Artinya, ketika anak memiliki kecerdasan intrapersonal maka anak mampu menyeimbangkan emosinya dan juga fisiknya. Keempat, mengendalikan dan mengarahkan emosi. Artinya, anak mampu mengendalikan emosinya dan anak dapat mengetahui kemana arah 
emosi anak dan anak dapat mengambil tindakan dnegan bijak.

Kelima, mengatur dan memotivasi diri. Anak yang memiliki kecerdasan intrapersonal maka mereka mampu memotivasi diri mereka sendiri. Keenam, bertanggungjawab atas kehidupan diri sendiri. ${ }^{6}$ Artinya anak mampu bertanggung jawab dengan diri mereka sendiri. Jika anak mampu bertanggung jawab dengan dirinya makan otomatis anak mampu bertanggung jawab untuk orang lain juga.

Anak dapat mengimpelementasikan kecerdasan intrapersonal yang ada dalam dirinya jika anak, terus menjalin relasi dengan orang-orang yang ada disekitarnya. Sehingga kepemimpinannya dapat di latih. Namun, dalam hal ini orangtua bisa memberikan motifasi dan dorongan kepada anak sehingga anak bisa mendapat stimulus dari orangtua. Orangtua juga bisa menjalin kerja sama dengan guru, sehingga guru juga mampu memberikan anak stimulus yang sama sehingga anak lebih bergairah untuk mengimplementasikan kecerdasan intrapersonal yang ada dalam dirinya untuk melatih kepemimpinannya.

\footnotetext{
${ }^{6}$ Lwin et al., Cara Mengembangkan Berbagai
} Komponen Kecerdasan.

\section{Definisi Kepemimpinan}

Stephen Robbins dan Timothy Judge mendefenisikan kepemimpinan sebagai kemampuan untuk memengaruhi suatu kelompok menuju pencapaian sebuah visi atau tujuan yang ditetapkan. Trianto Safira dalam bukunya mengutip pendapat Joseph C. Rost yang menyatakan bahwa, kepemimpinan adalah hubungan saling memengaruhi antara pemimpin dan pengikut yang menginginkan perubahan nyata sebagai tujuan bersama.

John M Bryson juga mendefenisikan kepemimpinan sebagai kemampuan menginspirasi dan memobilisasi orang-orang untuk melakukan kegiatan kelompok bagi kepentingan bersama. Selanjutnya Trianto Safira juga mengutip pendapat James

MacGregor Burns yang menyatakan bahwa kepemimpinan atas manusia dilaksanakan dengan memberi motivasi dan tujuan tertentu, menggerakkan sumber daya sehingga membangkitkan keterlibatan para pengikutnya. $^{7}$

\footnotetext{
${ }^{7}$ Ahmad Tabrani, "Pengaruh Kepemimpinan Dan Mentoring Terhadap Motifasi Dalam Melayani," Edulead 1, no. 1 (2020), https://journals.indexcopernicus.com/api/file/view ByFileId/1125203.pdf.
} 
Dengan beberapa definisi di atas dapat disimpulkan bahwa kepemimpinan yaitu tentang bagaimana memberikan pengaruh atau dampak kepada orang lain. Oleh karena itu, anak setelah mampu memahami, orang-orang yang ada di sekitar mereka maka anak akan mampu mempengaruhi dengan gaya kepemimpinan yang ada dalam diri mereka masing-masing.

\section{Cara Melatih Kepemimpinan Anak}

Melatih kepemimpinan anak bisa dilakukan oleh guru dan orangtua. Orangtua dan juga bisa terus mendorong anak sehingga kepemimpinan yang ada dalam diri anak, dapat mereka kembangkan. Oleh karena itu ada beberapa cara untuk dapat melatih kepemimpinan yang ada dalam diri anak yaitu pertama, membantu mereka belajar untuk melihat sudut pandang yang berbeda dalam situasi kelompok dimana terdapat pendapat yang variatif. Artinya, anak mampu beradapati dengan melihat setiap sudut pandang orang lain yang berbeda-beda. Hal ini juga melatih kepemimpinan yang ada dalam diri anak.

Seorang pemimpin yang baik tidak menyatakan dirinya seorang pemimpin, tetapi dipilih oleh rekan-rekannya untuk menjadi seorang pemimpin. Dengan demikian, tujuan akhirnya adalah untuk tidak mengajar anak bagaimana menjadi pemimpin, tetapi untuk mengajarinya dasar etika dan nilai-nilai sehingga anak menjadi individu yang kuat dengan kemampuan untuk menjadi seorang pemimpin. Anak-anak dapat diajarkan juga keterampilan di usia dini karena pikiran mereka masih sangat mudah ingin tahu dan waspada sebuah identitas. Dengan bimbingan guru anak juga akan belajar bagaimana berkomunikasi secara efektif, strategi, menangani situasi rumit, tidak ditekan, dan merencanakan segala sesuatu di awal. Memberikan contohcontoh nyata yang terjadi, sehingga anak bagaimana disiplin, dan bersifat proaktif karena hal tersebut dapat membuat anak menonjol dan sukses. Kedua, membantu mereka mempertahankan sikap positif ketika orang lain membuat hal-hal sulit untuk mengatakan bahwa mereka tidak dapat mencapai sesuatu. Ketiga, ajarkan anak bahwa kesahalan akan selalu terjadi dan merupakan bagian alami dari kehidupan, dan tidak membiarkan kesalahan mengalahkan semangat anak untuk lebih baik lagi. Ajarkan anak untuk bertanya pada diri sendiri apa yang bisa dilakukan untuk menghadapi situasi yang sulit. Keempat, mendaftarkan anak-anak dalam kegiatan ekstrakurikuler untuk memberikan mereka kepercayaan diri yang dibutuhkan dalam memimpin orang lain. Kelima, belajar bijaksana terhadap denga uang, mampu mengelolah uang 
dengan baik sangat penting jika ingin anak menjadi seorang pemimpin. Keenam, pengambilan keputusan. Para pemimpin yang baik harus mampu membuat keputusan yang baik. Ketujuh pembinaan agama. Pembinaan agama yang dibuat oleh orangtua atau guru sangat bermanfaat bagi anak, yaitu salah satunya mampu menjadi sosok pribadi yang bijaksana, yang tentu saja dibutuhkan oleh figur pemimpin. $^{8}$

$\begin{array}{rrr}\text { Alasan } & \text { pentingnya melatih } \\ \text { kecerdasan } & \text { intrapersonal dalam }\end{array}$
meningkatkan kepemimpinan anak yaitu, harapan penulis anak bisa memahami orang-orang yang ada di sekitarnya. Orangtua juga menyadari bahwa melatih kecerdasan intrapersonal anak sangatlah penting untuk dilakukan. Sehingga orangtua bisa terus memberikan dorongan kepada anak, agar anak bisa meningkatkan kepemimpinan yang ada dalam dirinya lewat implementasi kecerdasan intrapersonal. Hal ini juga penting bagi guru sebagai pendidik, untuk bisa menstimulus anak, agar anak mampu melatih kecerdasan intrapersonal yang ada di dalam dirinya dan kepemimpinan anak juga bisa terlatih.

\footnotetext{
${ }^{8}$ Roni Rodiyana and Wina Dwi Puspitasari, "MENUMBUHKAN KEPEMIMPINAN ANAK DI SEKOLAH DASAR,” Jurnal Cakrawala Pendas 5, no. 2 (July 2, 2019), https://jurnal.unma.ac.id/index.php/CP/article/view $/ 1442$.
}

\section{KESIMPULAN}

Dapat disimpulkan bahwa agar anak dapat mengimplementasikan kecerdasan intrapersonal yang ada dalam dirinya untuk melatih kepemimpinannya, maka anak harus mampu menjalin relasi dengan orang-orang yang ada disekitarnya, mampu memahami secara holistik, baik sikap, perilaku, emosi, dan semua yang bersifat tentang orang lain. Selain itu, orangtua dan juga guru bisa memberikan stimulus kepada anak. Sehingga anak, tidak merasa sendiri dalam anak melakukannya. Dan akhrinya jika hal ini diterapkan maka dapat terlakasana sesuai dengan tujuan yang diharapkan. 


\section{DAFTAR PUSTAKA}

Acesta, Aroffa. Kecerdasan Kinestetik

Dan Interpersonal Serta

Pengembangannya. Surabaya, 2019.

Lwin, May, Adam Khoo, Kenneth Lyen, and caroline sim. Cara

Mengembangkan Berbagai

Komponen Kecerdasan. Yogyakarta:

Prentice-Hall Inc, 2005.

Nisa, Ana Fitrotun. "Implementasi

Multiple Intelligences Dalam

Pendidikan Dasar." Jurnal

pendidikan dasar islam 7, no. 2

(n.d.).

https://www.neliti.com/id/publication s/284542/implementasi-multiple-

intelligences-dalam-pendidikan-

dasar.

Rodiyana, Roni, and Wina Dwi

Puspitasari. "MENUMBUHKAN

KEPEMIMPINAN ANAK DI

SEKOLAH DASAR.” Jurnal

Cakrawala Pendas 5, no. 2 (July 2,

2019).

https://jurnal.unma.ac.id/index.php/C

P/article/view/1442.

Sujiono, Yuliani Nurani. Metode

Pengembangan Kognitif. Jakarta,

2009.

Tabrani, Ahmad. "Pengaruh

Kepemimpinan Dan Mentoring

Terhadap Motifasi Dalam Melayani.”

Edulead 1, no. 1 (2020).

https://journals.indexcopernicus.com/
api/file/viewByFileId/1125203.pdf.

Zed, Mestika. Metode Penelitian

Kepustkaan. Jakarta, 2008.

https://books.google.co.id/books?id=i IV8zwHnGo0C\&printsec $=$ frontcover $\& d q=$ penelitian + kepustakaan+adalah $\& h l=i d \& s a=X \& v e d=2 a h U K E w i f \_Z v$ u1p3vAhWH7nMBHdXzAakQ6AE wAHoECAEQAg\#v=onepage $\& \mathrm{q}=$ pe nelitian kepustakaan adalah $\& \mathrm{f}=\mathrm{false}$. 